Technological University Dublin

ARROW@TU Dublin

\title{
One-Pot Synthesis of Anionic (Nitrogen) and Cationic (Sulfur) Codoped High-Temperature Stable, Visible Light Active, Anatase Photocatalysts
}

\author{
Suresh Pillai \\ Technological University Dublin, suresh.pillai@tudublin.ie \\ Declan McCormack \\ Technological University Dublin, Declan.mccormack@tudublin.ie \\ Steven Hinder
}

See next page for additional authors

Follow this and additional works at: https://arrow.tudublin.ie/cenresart

Part of the Chemical Engineering Commons, Inorganic Chemistry Commons, Materials Chemistry Commons, Nanoscience and Nanotechnology Commons, and the Physical Chemistry Commons

\section{Recommended Citation}

Periyat, P., McCormack, D., Hinder, S., Pillai, S. (2009): One-Pot Synthesis of Anionic (Nitrogen) and Cationic (Sulfur) Codoped High-Temperature Stable, Visible Light Active, Anatase Photocatalysts. Journal of physical chemistry C, 113,(8), 2009, pp. 3246-3253. doi:10.1021/jp808444y

This Article is brought to you for free and open access by the Crest: Centre for Research in Engineering Surface Technology at ARROW@TU Dublin. It has been accepted for inclusion in Articles by an authorized administrator of ARROW@TU Dublin. For more information, please contact arrow.admin@tudublin.ie, aisling.coyne@tudublin.ie,gerard.connolly@tudublin.ie.

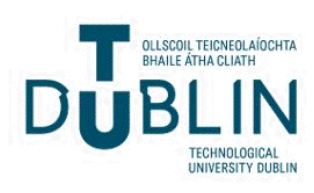




\section{Authors}

Suresh Pillai, Declan McCormack, Steven Hinder, and Pradeepan Periyat 
Dublin Institute of Technology

ARROW@DIT

One-Pot Synthesis of Anionic (Nitrogen) and Cationic (Sulfur) Codoped High-Temperature Stable, Visible Light Active, Anatase Photocatalysts

Suresh C. Pillai

Declan McCormack

John Colreavy

Pradeepan Periyat 


\title{
One-Pot Synthesis of Anionic (Nitrogen) and Cationic (Sulfur) Codoped High-Temperature Stable, Visible Light Active, Anatase Photocatalysts
}

\author{
Pradeepan Periyat, ${ }^{\dagger, *}$ Declan E. McCormack, ${ }^{*, \star}$ Steven J. Hinder, ${ }^{\S}$ and Suresh C. Pillai ${ }^{*, \dagger}$ \\ Centre for Research in Engineering Surface Technology (CREST), FOCAS Institute, Dublin Institute of \\ Technology, Camden Row, Dublin 8, Ireland, School of Chemical and Pharmaceutical Sciences, Dublin \\ Institute of Technology, Kevin Street, Dublin 8, Ireland, and The Surface Analysis Laboratory, School of \\ Engineering, University of Surrey, Guildford, Surrey GU2 7XH, U.K.
}

Received: September 23, 2008; Revised Manuscript Received: December 09, 2008

\begin{abstract}
An efficient and straightforward method for the preparation of nitrogen and sulfur $(\mathrm{N}, \mathrm{S})$ codoped high-temperature stable, visible light active, anatase titania is reported. For the first time simultaneous nitrogen and sulfur doping was achieved using a single source, ammonium sulfate $\left[\left(\mathrm{NH}_{4}\right)_{2} \mathrm{SO}_{4}\right]$, as the modification agent of the titanium isopropoxide (TTIP) precursor. A stoichiometric modification of 1:8 TTIP: $\left(\mathrm{NH}_{4}\right)_{2} \mathrm{SO}_{4}$ composition (TNS8) was found to be the most effective in extending the stability of anatase to higher temperatures. This particular modification resulted in $100 \%$ anatase at $850{ }^{\circ} \mathrm{C}$ and $41 \%$ anatase at $900{ }^{\circ} \mathrm{C}$, whereas the control titania contained only $12 \%$ anatase at $700{ }^{\circ} \mathrm{C}$ and completely transformed to rutile at $800{ }^{\circ} \mathrm{C}$. Codoped $(\mathrm{N}, \mathrm{S})$ titania was investigated by a range of characterization techniques including XRD, Raman spectroscopy, XPS, and FTIR. XPS indicated the existence of nitrogen as an anion dopant and sulfur as a cation dopant within the $\mathrm{TiO}_{2}$ lattice. The $\mathrm{UV} / \mathrm{visible}$ and visible light photocatalytic studies were carried out using the rhodamine $6 \mathrm{G}$ dye as a model system. The visible light photocatalytic activity of the TNS8 sample calcined at $850{ }^{\circ} \mathrm{C}$ was double that of Degussa P25, and the rate constant calculated by pseudo-first-order kinetics was $0.019 \mathrm{~min}^{-1}$ for the TNS8 sample and $0.008 \mathrm{~min}^{-1}$ for Degussa P25. This higher photocatalytic activity was attributable to a combination of improved anatase phase stability, higher surface area, and codoped (N, S) titania lattice. Moreover, this codoped (N, S) sample also exhibits excellent photocatalytic activity under UV/visible light.
\end{abstract}

\section{Introduction}

Nanocrystalline titania is considered to be an eco-friendly material and has found applications in various fields such as photovoltaics, photocatalysis, self-cleaning coatings, and nanochromic display devices. ${ }^{1-5}$ Among the three forms of titania (anatase, rutile, and brookite), anatase usually exhibits the highest photocatalytic activity. The higher adsorption affinity toward organic compounds, along with the lower electron-hole recombination rate of anatase, phase makes it a superior photocatalyst. ${ }^{6,7}$ The anatase phase is irreversibly converted to the less reactive rutile phase at $500-600{ }^{\circ} \mathrm{C}$ under normal conditions, ${ }^{2,8-10}$ which limits its suitability for high-temperature applications. Many proposed innovative and commercial applications for photocatalytically active stable titania-coated materials such as bathroom tiles, sanitary wares, and selfcleaning glass for the control of organic contaminants require high processing temperatures and hence high-temperature stability. ${ }^{2,11,12}$ High consumer demand is projected for these materials. To date most of the work reported to improve the thermal stability of anatase titania utilizes metal ion doping. ${ }^{13-15}$ This method, which involves the addition of inorganic oxides (e.g., $\mathrm{Al}_{2} \mathrm{O}_{3}, \mathrm{CeO}_{2}$ ) to generate metal ions at higher temperatures, has successfully been used to control the anatase-to-rutile

\footnotetext{
* Authors for correspondence. E-mail: suresh.pillai@dit.ie; declan. mccormack@dit.ie.

Centre for Research in Engineering Surface Technology (CREST), FOCAS Institute, Dublin Institute of Technology.

School of Chemical and Pharmaceutical Sciences, Dublin Institute of Technology.

$\S$ The Surface Analysis Laboratory, School of Engineering, University of Surrey.
}

transformation temperature as well as improve the photocatalytic activity of titania. However, the drawback of this method is the generation of secondary impurity phases (e.g., $\mathrm{Al}_{2} \mathrm{TiO}_{5}$, $\mathrm{CeTi}_{4} \mathrm{O}_{24}$, and $\mathrm{Ce}_{2} \mathrm{Ti}_{2} \mathrm{O}_{7}$ ) which affects phase purity and thus reduces the photocatalytic activity of titania. ${ }^{16}$

Chemical modification of a precursor is considered a superior method to the conventional method of metal ion doping, since it eliminates the secondary impurity phase formation. Sulfate impregnation of $\mathrm{TiO}_{2}$ has recently been reported to improve the photocatalytic activity of titania. ${ }^{17-19}$ For example, Colon et al. reported using this methodology to improve the phase stability of anatase up to $700{ }^{\circ} \mathrm{C}$. They also noted the higher photocatalytic activity for the impregnated sample compared to the unmodified one. However, these materials converted to rutile phase at $800{ }^{\circ} \mathrm{C}$, and subsequently the photocatalytic activity was also reduced. ${ }^{18}$ The $\left(\mathrm{NH}_{4}\right)_{2} \mathrm{SO}_{4}$ impregnation on $\mathrm{TiO}_{2}$ reported by Ortiz-Islas et al. showed brookite and mascagnite phase as an impurity. ${ }^{20}$ Furthermore the complete phase transformation to rutile occurred in the range 650-50 ${ }^{\circ} \mathrm{C}$. The effect of the $\mathrm{SO}_{4}{ }^{2-}$ and $\mathrm{Cl}^{-}$ions on the formation of anatase by the low-temperature, microemulsion modified hydrothermal method has also been reported. ${ }^{21}$ Bokhimi et al. reported a comparative study of two different $\mathrm{Cu}$ precursors $\left(\mathrm{CuCl}_{2}\right.$ and $\left.\mathrm{CuSO}_{4}\right)$ for anatase stabilization, and the $\mathrm{CuSO}_{4}$ addition retained $98 \%$ anatase at $800{ }^{\circ} \mathrm{C} .{ }^{22}$ However the stabilization explained in this study was due to the combined effect of metal ion $\left(\mathrm{Cu}^{2+}\right)$ and $\mathrm{SO}_{4}{ }^{2-}$. Moreover the secondary impurity phases bonattite and antierite were generated after annealing the sample at 400 and $800{ }^{\circ} \mathrm{C}$, respectively. We have recently reported the chemical modification of titanium isopropoxide by using different nonmetallic chemical reagents such 
as urea, sulfuric acid, and trifluoroacetic acid to improve the anatase stability and the photocatalytic activity by doping with nitrogen, sulfur, and fluorine, respectively.,2,,23

This paper outlines the preparation of an N, S codoped anatase titania having high-temperature stability and visible-light photocatalytic activity by chemically modifying titanium isopropoxide precursor. The codoping (N, S) was achieved by using a single dopant precursor ammonium sulfate $\left[\left(\mathrm{NH}_{4}\right)_{2} \mathrm{SO}_{4}\right]$. This effectively performs a dual role during the chemical modification process by stabilizing the anatase phase at higher temperature and serving as a source for both nitrogen and sulfur dopants to improve the photocatalytic activity of the high-temperature stabilized anatase titania. With this method the phase composition can be tuned by simply varying the molar ratio of ammonium sulfate to titania precursor. This modification has also resulted in increased temperature stability of anatase phase up to $900{ }^{\circ} \mathrm{C}$ ( $41 \%$ anatase), an increase in surface area, and a higher visible light photocatalytic activity than the standard Degussa P25. Recent studies using thiourea showed that either nitrogen or sulfur was doped in the titania lattice. ${ }^{24,28}$ Surprisingly here we achieved combined anionic (nitrogen) and cationic (sulfur) doping in the titania lattice from the use of the single precursor ammonium sulfate $\left[\left(\mathrm{NH}_{4}\right)_{2} \mathrm{SO}_{4}\right]$.

\section{Experimental Section}

2.1. Procedure. The reagents used in this study were titanium isopropoxide (TTIP, $97 \%$, Aldrich), ammonium sulfate $\left[\left(\mathrm{NH}_{4}\right)_{2} \mathrm{SO}_{4}\right.$ 99\%, Riedel-de Haen, Germany], and deionized water. In a typical experiment conducted to prepare a 1:1 titania precursor:ammonium sulfate precursor solution, $29.7 \mathrm{~mL}(100 \mathrm{mmol})$ titanium isopropoxide $\left(\mathrm{Ti}(\mathrm{OPr})_{4}\right)$ was placed in $250 \mathrm{~mL}$ beaker. To the above solution was slowly added, $5 \mathrm{~mL}$ at a time with stirring, a solution of $13.2 \mathrm{~g}(100 \mathrm{mmol})$ of $\left(\mathrm{NH}_{4}\right)_{2} \mathrm{SO}_{4}$ dissolved in $180 \mathrm{~mL}$ of water. This was stirred for a further $15 \mathrm{~min}$ and then dried at $100{ }^{\circ} \mathrm{C}$ in an oven for $24 \mathrm{~h}$. A similar procedure was adopted to synthesize 1:4 1:8, 1:10, and 1:12 samples. Samples were named as TNS1, TNS4, TNS8, TNS10, and TNS12, respectively. For TNS12 sample preparation, the ammonium sulfate did not dissolve completely in $180 \mathrm{~mL}$ of water but formed a highly saturated solution. This was used for further reaction with TTIP. A control sample without any ammonium sulfate was also prepared to act as a comparison. All samples were calcined at $700,800,850$, and $900{ }^{\circ} \mathrm{C}$. X-ray diffraction (XRD) patterns of the calcined sample were obtained with a Siemens D $500 \mathrm{X}$-ray diffractometer in the diffraction angle range $2 \theta=10-70^{\circ}$ using $\mathrm{Cu} \mathrm{K} \alpha$ radiation. The amount of anatase in the sample was estimated using the Spurr equation (eq 1).

$$
F_{\mathrm{A}}=100-\left(\frac{1}{1+0.8\left(I_{\mathrm{A}}(101) / I_{\mathrm{R}}(110)\right.}\right) 100
$$

where $F_{\mathrm{A}}$ is the mass fraction of anatase in the sample, $I_{\mathrm{A}}(101)$ and $I_{\mathrm{R}}(110)$ are the integrated main peak intensities of anatase and rutile, respectively.

Raman measurements were taken using an Instruments S.A. (Jobin Yvon) Labram 1B. A helium-neon laser (514 nm) was used as laser source. BET (Brunauer, Emmett and Teller) surface area and pore size measurements were carried out by nitrogen adsorption using a Quantachrome NOVA 2000e surface area analyzer. The measurements were carried out at liquid nitrogen temperature after degassing the powder samples for $2 \mathrm{~h}$ at 200 ${ }^{\circ} \mathrm{C}$. The FTIR spectra of the sample were measured using a Spectrum GX-FTIR spectrophotometer in the range 4000-400 $\mathrm{cm}^{-1}$ using 32 scans per sample. X-ray Photoelectron Spectroscopy (XPS) analysis was performed on a Thermo VG Scientific (East Grinstead, U.K.) Sigma Probe spectrometer. The instrument employs a monochromated $\mathrm{Al} \mathrm{K} \alpha \mathrm{X}$-ray source $(\hbar v$
TABLE 1: Percentage of anatase and rutile present in control and modified samples at different temperatures ${ }^{a}$

\begin{tabular}{|c|c|c|c|c|c|c|c|c|c|c|}
\hline \multirow[b]{3}{*}{ sample } & \multicolumn{10}{|c|}{ temperature } \\
\hline & \multicolumn{2}{|c|}{$700{ }^{\circ} \mathrm{C}$} & \multicolumn{2}{|c|}{$800^{\circ} \mathrm{C}$} & \multicolumn{2}{|c|}{$850^{\circ} \mathrm{C}$} & \multicolumn{2}{|c|}{$900{ }^{\circ} \mathrm{C}$} & \multicolumn{2}{|c|}{$1000{ }^{\circ} \mathrm{C}$} \\
\hline & A & $\mathrm{R}$ & A & $\mathrm{R}$ & A & $\mathrm{R}$ & A & $\mathrm{R}$ & A & $\mathrm{R}$ \\
\hline TNS1 & 100 & 0 & 59 & 41 & 22 & 78 & 0 & 100 & 0 & 100 \\
\hline TNS4 & 100 & 0 & 96 & 4 & 76 & 24 & 9 & 91 & 0 & 100 \\
\hline TNS8 & 100 & 0 & 100 & 0 & 100 & 0 & 41 & 59 & 0 & 100 \\
\hline TNS 10 & 100 & 0 & 100 & 0 & 100 & 0 & 40 & 60 & 0 & 100 \\
\hline TNS12 & 100 & 0 & 100 & 0 & 100 & 0 & 19 & 81 & 0 & 100 \\
\hline control & 12 & 82 & 0 & 100 & 0 & 100 & 0 & 100 & 0 & 100 \\
\hline
\end{tabular}

${ }^{a}$ Error $\pm 5 \%$.

$=1486.6 \mathrm{eV}$ ) which was used at $140 \mathrm{~W}$. The area of analysis was approximately $500 \mu \mathrm{m}$ diameter for each sample analyzed.

2.2. Photocatalysis Studies. The visible and UV/visible light photocatalytic activity was performed by the following approach. In a typical experiment $0.06 \mathrm{~g}$ of calcined sample was dispersed in $50 \mathrm{~mL}$ of rhodamine $6 \mathrm{G}$ solution having a concentration 5 $\times 10^{-6} \mathrm{M}$. The above suspension was stirred for $30 \mathrm{~min}$ in the dark to obtain adsorption-desorption equilibrium to eliminate the error due to any initial adsorption effect. This was then irradiated in a Q-Sun Xenon solar simulator chamber having a wavelength range from 200 to $800 \mathrm{~nm}$ with an irradiation power $0.68 \mathrm{~W} / \mathrm{m}^{2}$. A cutoff filter $(\lambda=420 \mathrm{~nm})$ was used for the visible light photocatalysis to eliminate the UV light coming from the solar simulator. Degradation was monitored by taking 3-mL aliquots at different intervals of time. These aliquots were centrifuged for $15 \mathrm{~min}$ prior to absorbance measurements in order to eliminate the error due to scattering. Photocatalysis studies under UV/visible light were carried out by the same method without a filter.

\section{Results}

3.1. Anatase Phase Stability by XRD and Raman Studies. XRD analysis of the codoped (N, S) samples displayed higher anatase phase stability compared to the control titania prepared under identical conditions. Table 1 represents the fraction of anatase and rutile present in the codoped $(\mathrm{N}, \mathrm{S})$ and control sample at different calcination temperatures calculated using eq 1 . All codoped samples show only anatase phase (100\%) at $700{ }^{\circ} \mathrm{C}$. In contrast the control sample was predominately rutile phase $(88 \%)$. Even though $\left(\mathrm{NH}_{4}\right)_{2} \mathrm{SO}_{4}$ modification is effective in extending anatase phase stability in all instances, the effect is less in the lower molar ratio samples. The trend is clearly evident from Table 1 and Figures 1, 2, and 3. At 800 and 850 ${ }^{\circ} \mathrm{C}$ the TNS8 sample is $100 \%$ anatase phase, whereas the control titania was already completely converted to rutile phase at 800 ${ }^{\circ} \mathrm{C}$. The TNS4 and TNS 8 modification was found to be very effective in increasing the anatase phase stability (9\% and $41 \%$ anatase phase, respectively, at $900{ }^{\circ} \mathrm{C}$ ). The optimum level of modification is identified as TNS8. Raman spectroscopy was also applied to study the high-temperature stability of codoped titania as anatase and rutile phases have different Raman active modes. ${ }^{25}$ Figure 4, spectra a and b, are respectively the Raman spectra of the TNS8 and control sample calcined at $800{ }^{\circ} \mathrm{C}$. All the peaks present in the TNS8 sample were due to the anatase phase at 399,513 , and $639 \mathrm{~cm}^{-1} \cdot 25,26$ In contrast the control sample with peaks at 230,446 , and $612 \mathrm{~cm}^{-1}$ is clearly rutile phase. ${ }^{25,26}$ At $900{ }^{\circ} \mathrm{C}$ (Figure 4c) the TNS8 sample shows $41 \%$ anatase (as per XRD) which is confirmed by anatase peaks at $\left(399,513\right.$, and $\left.639 \mathrm{~cm}^{-1}\right)$ along with rutile peaks. These Raman results are consistent with the XRD data.

3.2. BET Surface Area Analysis. The physicochemical sorption properties and pore parameters of the TNS8 and control 
Nitrogen, Sulfur Codoped Anatase $\mathrm{TiO}_{2}$

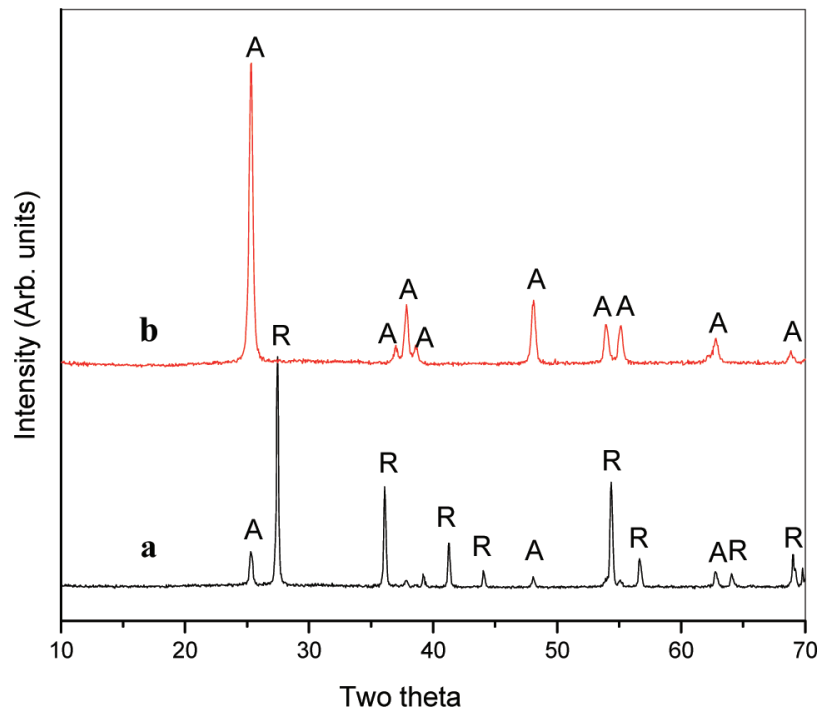

Figure 1. XRD spectra of the TNS8 calcined samples at $700{ }^{\circ} \mathrm{C}$ (a) and control (b).

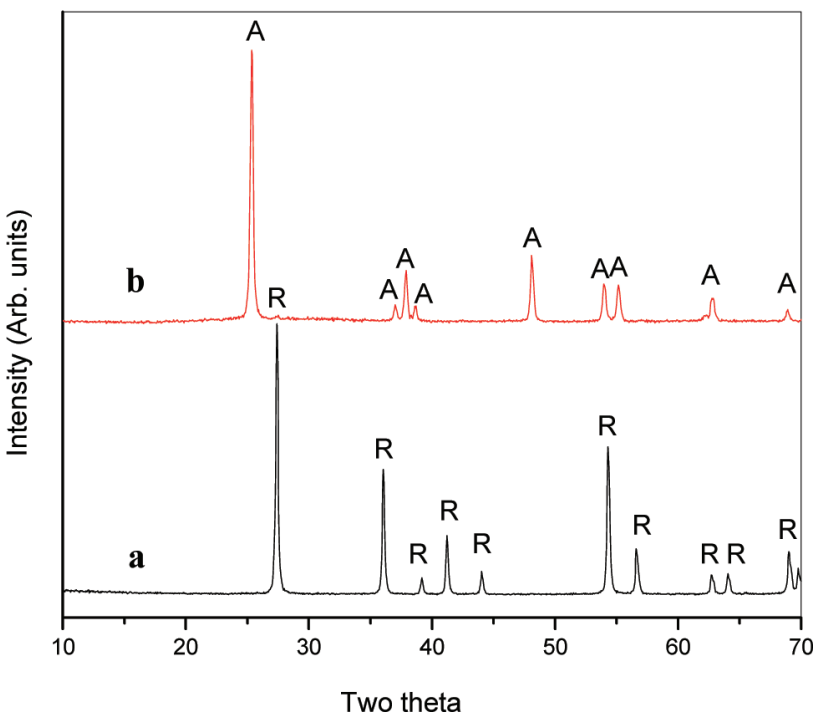

Figure 2. XRD spectra of the TNS 8 calcined samples at $800{ }^{\circ} \mathrm{C}$ (a) and control (b). titania samples calcined at 700,800 , and $900{ }^{\circ} \mathrm{C}$ are listed in Table 2. The nitrogen adsorption and desorption isotherm of the TNS8 and control sample shows type I isotherm (Supporting Information 1), indicating the pore size to be in the micropore range. The results indicated that the surface area and pore volume values decrease as the calcination temperature increases for both TNS8 and control sample. This is attributable to the collapse of the porous framework in both TNS8 and the control titania. This collapse was more pronounced in the control sample compared to the TNS8 sample. At $700{ }^{\circ} \mathrm{C}$ the control sample has a surface area value of $25.6 \mathrm{~m}^{2} / \mathrm{g}$, whereas the value for the TNS8 sample is $53.6 \mathrm{~m}^{2} / \mathrm{g}$. At $800{ }^{\circ} \mathrm{C}$ the surface areas are 1.9 and $30.1 \mathrm{~m}^{2} / \mathrm{g}$ for control and TNS8 respectively. This result indicates that the surface area decrease is more pronounced in the control compared to the codoped sample. The surface area of the TNS8 sample at $900{ }^{\circ} \mathrm{C}$ is $10 \mathrm{~m}^{2} / \mathrm{g}$, whereas the control using $\left(\mathrm{NH}_{4}\right)_{2} \mathrm{SO}_{4}$ was found to increase the surface area of titania significantly.

3.3. X-ray Photoelectron Spectroscopy (XPS). XPS measurements were carried out to investigate the $\mathrm{N}$ and $\mathrm{S}$ incorporation in the high-temperature stable anatase titania. The amount sample shows values only of $1 \mathrm{~m}^{2} / \mathrm{g}$. Therefore, the modification
J. Phys. Chem. C, Vol. xxx, No. xx, XXXX C

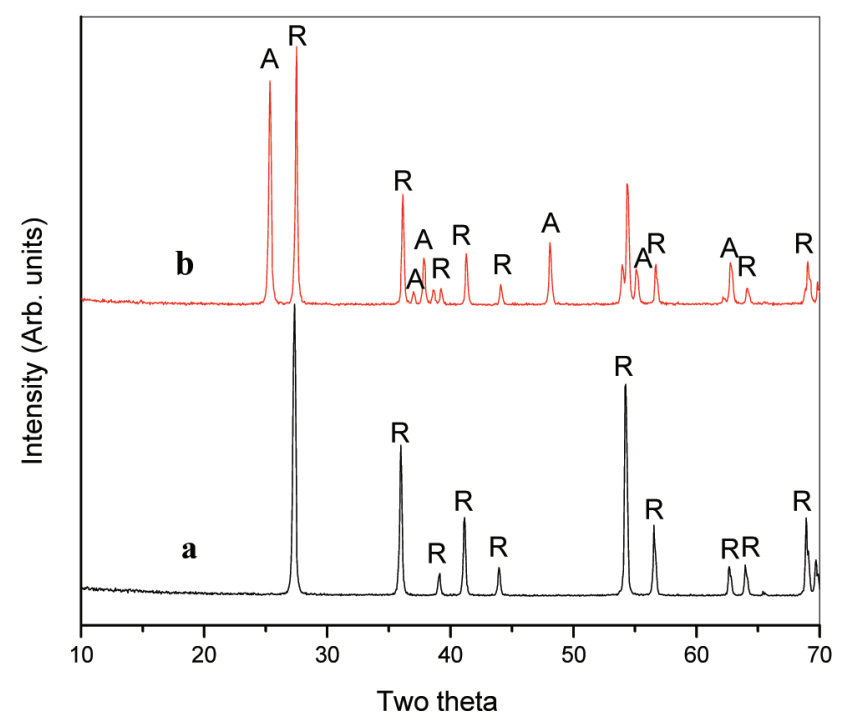

Figure 3. XRD spectra of the TNS8 calcined samples at $900{ }^{\circ} \mathrm{C}$ (a) and control (b).

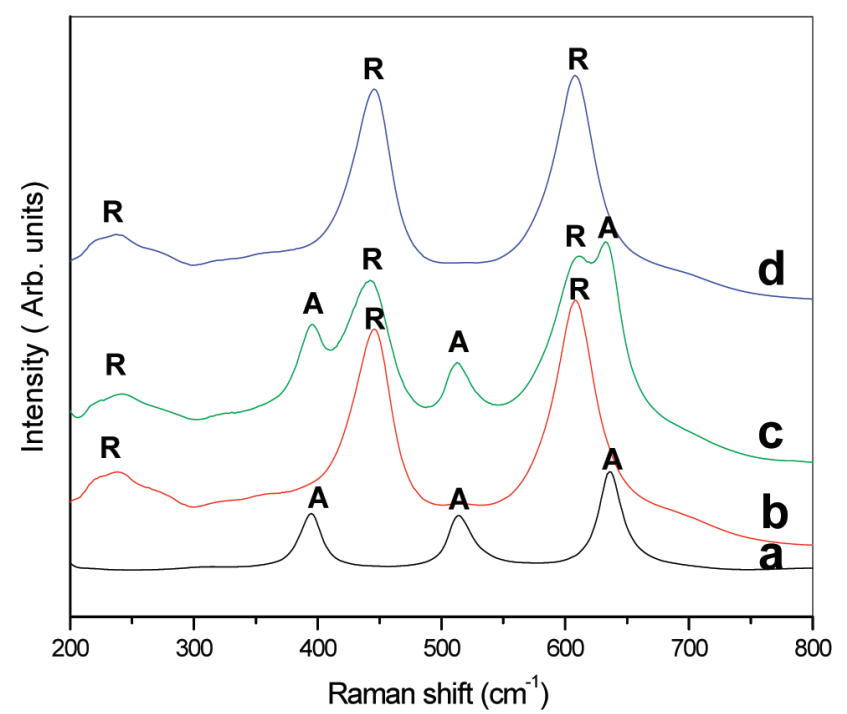

Figure 4. Raman spectra of (a) TNS 8 at $800{ }^{\circ} \mathrm{C}$, (b) control at 800 ${ }^{\circ} \mathrm{C}$, (c) TNS8 at $900{ }^{\circ} \mathrm{C}$, (d) control at $900{ }^{\circ} \mathrm{C}$.

TABLE 2: Surface area of the TNS8 and control titania at different temperatures.

\begin{tabular}{clcc}
\hline $\begin{array}{c}\text { temperature } \\
\left({ }^{\circ} \mathrm{C}\right)\end{array}$ & sample & $\begin{array}{c}\text { BET surface } \\
\text { area }\left(\mathrm{m}^{2} / \mathrm{g}\right)\end{array}$ & $\begin{array}{c}\text { pore volume } \\
\left(\mathrm{cm}^{3} / \mathrm{g}\right)\end{array}$ \\
\hline 700 & TNS8 & 53.3 & 0.256 \\
& control & 25.6 & 0.160 \\
800 & TNS8 & 30.1 & 0.120 \\
& control & 1.9 & 0.007 \\
900 & TNS8 & 10.0 & 0.022 \\
& control & 1.0 & 0.00
\end{tabular}

of nitrogen and sulfur in the TNS8 samples calcined at temperatures $600,700,800$, and $900{ }^{\circ} \mathrm{C}$ are shown in Table 3 . The amount of $\mathrm{N}$ and $\mathrm{S}$ at $600{ }^{\circ} \mathrm{C}$ is significant compared to those obtained at higher temperatures. Figure 5 represents the XPS spectra of nitrogen and sulfur present in the TNS8 sample calcined at 600 and $800{ }^{\circ} \mathrm{C}$. In Figure 5a, the binding energy peak for N-doped TNS8 sample at $600{ }^{\circ} \mathrm{C}$ is broad, extends from 398 to $405 \mathrm{eV}$, and is centered at $402 \mathrm{eV}$. This value is clearly greater than the typical binding energy $(396 \mathrm{eV})$ of the $\mathrm{Ti}-\mathrm{N}$ bond, suggesting that there is no $\mathrm{Ti}-\mathrm{N}$ bond formation. ${ }^{27}$ It was previously observed that the molecular chemisorbed 
TABLE 3: Amount of nitrogen and sulfur present in the TNS8 sample calcined at different temperatures ${ }^{a}$

\begin{tabular}{ccc}
\hline $\begin{array}{c}\text { calcination } \\
\text { temperature }\left({ }^{\circ} \mathrm{C}\right)\end{array}$ & $\begin{array}{c}\text { nitrogenqa } \\
\text { content }(\text { atom } \%)\end{array}$ & $\begin{array}{c}\text { sulfurqa } \\
\text { content }(\text { atom \%) }\end{array}$ \\
\hline 600 & 1.5 & 3.5 \\
700 & 0.4 & 0.7 \\
800 & 0.2 & 0.3 \\
900 & 0.1 & 0.2
\end{tabular}

${ }^{a}$ Error $\pm 5 \%$.

nitrogen shows a peak at around $400 \mathrm{eV}$, and NO in the metal lattice displays a peak at $401 \mathrm{eV} .{ }^{27} \mathrm{We}$ suggest that the peak at $402 \mathrm{eV}$ is due to the presence of both $\mathrm{NO}$ and chemisorbed $\mathrm{N}_{2}$ species. The reason behind this suggestion is that there is a strong possibility for the formation of both species due to decomposition of $\mathrm{NH}_{4}^{+}$present in the sample when the temperature is elevated. As the temperature increases, the 402 $\mathrm{eV}$ peak is slightly shifted toward a lower value, suggesting that further increase in temperature led to the doping of the nitrogen in the lattice of titania by the replacement of the oxygen atom. At $800{ }^{\circ} \mathrm{C}$ this peak shows a value at $400 \mathrm{eV}$ (Figure $5 \mathrm{c}$ ), and at $900{ }^{\circ} \mathrm{C}$ it is at $399.7 \mathrm{eV}$. This peak therefore can be attributed to the $1 \mathrm{~s}$ electron binding energy of the $\mathrm{N}$ atom in the $\mathrm{O}-\mathrm{Ti}-\mathrm{N}$ environment. ${ }^{27}$ This $\mathrm{O}-\mathrm{Ti}-\mathrm{N}$ bond formation occurs by the replacement of the lattice oxygen by nitrogen in $\left[\mathrm{TiO}_{6}\right]^{2-}$ octahedra (basic unit of titania) and can be represented by a general formula for anionic nitrogen doping $\mathrm{TiO}_{2-X} \mathrm{~N}_{X}$ as explained in the recent reports. ${ }^{27}$ Sulfur present in these samples has a peak around $169 \mathrm{eV}$ which does not show any further shift as the temperature increases. This peak at $169 \mathrm{eV}$ was previously explained as $\mathrm{S}^{6+}$ cation present in the titania lattice. ${ }^{18,28,29}$ Therefore, anionic and cationic doping was achieved in the same titania through this chemical modification method.

3.4. Photocatalytic Study. Photocatalytic studies were carried out using the decomposition reaction of rhodamine $6 \mathrm{G}$ dye in the presence of the TNS8 and control samples under UV and visible light. Pseudo-first-order degradation ${ }^{2}$ rate constants, obtained by plotting the natural logarithm of the absorbance against irradiation time for the TNS 8 and control samples calcined at different temperatures, are tabulated in Table 4. All the TNS8 samples calcined at different temperatures show significantly higher photocatalytic efficiency compared to the control titania prepared under identical condition. The photocatalytic activity of these codoped samples was also compared with that of the Degussa P25 photocatalyst. The highest photocatalytic activity was obtained for TNS8 sample calcined at $850{ }^{\circ} \mathrm{C}$. This sample has higher photocatalytic activity than the Degussa P25 sample both in UV/visible and visible light. The photocatalytic activity comparison of TNS8 samples with Degussa P25 are shown in the Table 4. Figures 6 and 7 show the kinetic data and absorption spectra of rhodamine dye in the presence of TNS8 sample under UV/visible and visible light in comparison with the Degussa P25 sample. The visible light activity of TNS8 sample (rate constant $0.019 \mathrm{~min}^{-1}$ ) is more than twice that of the Degussa P25 sample (rate constant 0.008 $\min ^{-1}$ ), whereas the control sample shows a negligible amount of visible light photocatalytic activity at this temperature (rate constant $0.001 \mathrm{~min}^{-1}$ ). For the control sample, the best photoactivity was shown by the sample calcined at $700{ }^{\circ} \mathrm{C}$ which has a high surface area (Table 2) compared to the same sample calcined at 800 and $900{ }^{\circ} \mathrm{C}$.

\section{Discussion}

4.1. Anatase Phase Stability. The two main processes involved in the formation of a metal oxide from metal alkoxides are hydrolysis and condensation. ${ }^{30}$ The reactivity of transition metal alkoxides, particularly titanium (IV) alkoxide, particularly in relation to hydrolysis and condensation is rapid. This is due to the presence of vacant d orbitals in the transition metals which help in the co-ordination expansion. ${ }^{31}$ Titanium (IV) alkoxide compounds when reacting with water increase the co-ordination number of the metal from 4 to 6 , by accepting the lone pair of electrons from the oxygen of the nucleophlic ligand $-\mathrm{O}-\mathrm{H}$ to form $\mathrm{Ti}(\mathrm{OH})_{z}\left(\mathrm{H}_{2} \mathrm{O}\right)_{6-z}(z-4)-32,21$ This structure undergoes dehydration and condensation to form a final precipitate of titanium hydroxide which generates crystalline titania $\left(\mathrm{TiO}_{2}\right)$ on further heat treatment. In order to avoid the fast reactivity toward hydrolysis and condensation, chemical additives (complexing molecules) are often added to moderate the rate of the reaction. ${ }^{25,31}$ Such control of hydrolysis and condensation reactions using urea ${ }^{2}$ and trifluoroacetic acid $^{9}$ has led to the formation of high-temperature stable $\mathrm{N}$ and $\mathrm{F}$ doped anatase titania as previously reported by this group.

In the present study a readily available compound, ammonium sulfate, was used as a chemical modifier which is able to generate a high-temperature, stabilized N, S codoped anatase titania. The initial reaction between ammonium sulfate and titanium isopropoxide precursor led to the formation of a mixture of compounds including ammonium titanate and titanium oxysulphate (Figure $8 \mathrm{~b}$ JCPDS file no. 81-1566). It undergoes structural changes on heat treatment due to the instability of ammonium and sulfate species present in the compound to form the high-temperature stabilized anatase titania above $600{ }^{\circ} \mathrm{C}$. The formation of these compounds suggests that both ammonium and sulfate species are capable of inhibiting the crystallization of rutile titania at a lower temperature (below $600{ }^{\circ} \mathrm{C}$ ), thereby retaining anatase titania to higher temperatures (above $600{ }^{\circ} \mathrm{C}$ ). The XRD of the TNS8 sample at $100^{\circ} \mathrm{C}$ shows mainly ammonium sulfate (JCPDS file no. 41-0621). This is stable up to $300{ }^{\circ} \mathrm{C}$; however, the formation of anatase $\mathrm{TiO}_{2}$ in very small quantity is also visible here which is represented by a broad peak around the $2 \theta$ value at 25.3 in Figure 8a. Further heat treatment performed for this compound at a temperature of $400{ }^{\circ} \mathrm{C}$ generated the ammonium titanate and titanium oxysulphate (Figure 8b). Above $400{ }^{\circ} \mathrm{C}$ this forms the nitrogen-doped titanium oxysulphate structure (Figure 8c, JCPDS file no. 81-1566) due to the decomposition of ammonium ions. Our previous report showed that the titanium oxysulphate decomposes at a temperature of 620 ${ }^{\circ} \mathrm{C}$ to produce the sulfur-doped anatase titania. ${ }^{23}$ Therefore, further heat treatment of the above titanium oxysulphate causes its decomposition over a temperature above $600{ }^{\circ} \mathrm{C}$ to produce the $\mathrm{N}, \mathrm{S}$ codoped anatase titania. The general reaction series can be represented by the following equations.

$$
\begin{array}{r}
4 \mathrm{Ti}(\mathrm{OPr})_{4}+\left(\mathrm{NH}_{4}\right)_{2} \mathrm{SO}_{4}+8 \mathrm{H}_{2} \mathrm{O} \stackrel{100 \cdots 400}{\longrightarrow}\left(\mathrm{NH}_{4}\right)_{2} \mathrm{Ti}_{3} \mathrm{O}_{7}+ \\
\mathrm{TiOSO}_{4}+16\left(\mathrm{CH}_{3}-\mathrm{CH}(\mathrm{OH})-\mathrm{CH}_{3}\right) \\
\left(\mathrm{NH}_{4}\right)_{2} \mathrm{Ti}_{3} \mathrm{O}_{7}+\mathrm{TiOSO}_{4}+3 \mathrm{O}_{2} \stackrel{400-600}{\longrightarrow} \mathrm{TiO}_{1-x} \mathrm{SO}_{4} \mathrm{~N}_{x}+ \\
\mathrm{TiO}_{2-x} \mathrm{~N}_{x}+2 \mathrm{TiO}_{2}+2(1-x) \mathrm{NO}_{2}+4 \mathrm{H}_{2} \mathrm{O} \\
2 \mathrm{TiO}_{1-x} \mathrm{SO}_{4} \mathrm{~N}_{x}+\mathrm{TiO}_{2-x} \mathrm{~N}_{x} 3 \mathrm{Ti}_{1-y} \mathrm{~S}_{y} \mathrm{O}_{2-x} \mathrm{~N}_{x}+
\end{array}
$$$$
(2-y) \mathrm{SO}_{2}+\mathrm{O}_{2}
$$

Therefore, the $\mathrm{SO}_{4}{ }^{2-}$ ion which is stable up to a temperature of $620^{\circ} \mathrm{C}$ plays a major role in stabilizing the anatase structure along with $\mathrm{NH}_{4}{ }^{+}$cation. IR spectroscopy reveals the role of the ammonium and sulfate species in the stabilization of the 

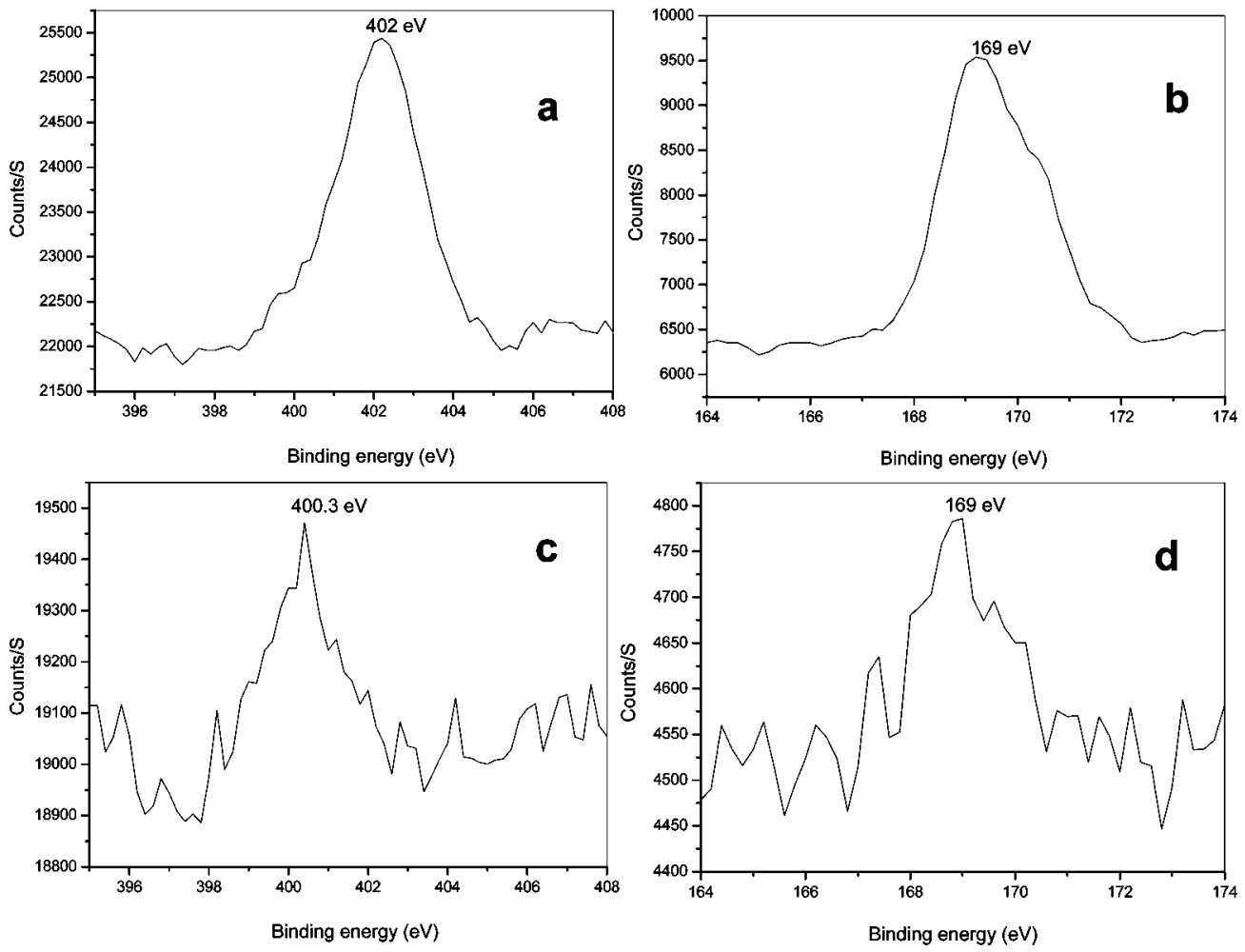

Figure 5. XPS spectra of (a) nitrogen and (b) sulfur at $600{ }^{\circ} \mathrm{C}$; (c) nitrogen and (d) sulfur at $800{ }^{\circ} \mathrm{C}$.

TABLE 4: Rate constants of the Degussa P25, TNS8, and control titania at different temperatures

\begin{tabular}{|c|c|c|c|c|c|c|c|c|c|}
\hline \multirow{3}{*}{ light source } & \multicolumn{9}{|c|}{ rate constant of the samples (units) } \\
\hline & \multirow{2}{*}{ Degussa } & \multicolumn{4}{|c|}{ TNS8 } & \multicolumn{4}{|c|}{ Control } \\
\hline & & \multicolumn{4}{|c|}{ temperature $\left({ }^{\circ} \mathrm{C}\right)$} & \multicolumn{4}{|c|}{ temperature $\left({ }^{\circ} \mathrm{C}\right)$} \\
\hline UV & 0.281 & 0.259 & 0.358 & 0.576 & 0.156 & 0.101 & 0.057 & 0.022 & 0.022 \\
\hline visible & 0.008 & 0.014 & 0.016 & 0.019 & 0.008 & 0.004 & 0.002 & 0.002 & 0.001 \\
\hline
\end{tabular}

anatase phase as well as the formation of $\mathrm{N}, \mathrm{S}$ codoped anatase titania. The IR spectra of the TNS8 sample shown in Figure 9 ( $a, b$, and c) have three main peaks at 612, 1104, and 1400 $\mathrm{cm}^{-1}$. Earlier reports showed the surface-adsorbed $\mathrm{SO}_{4}{ }^{2-}$ species has a band around $1250-1000 \mathrm{~cm}^{-1} .^{33}$ The peak around 1104 $\mathrm{cm}^{-1}$ is due to the interaction of $\mathrm{SO}_{4}{ }^{2-}$ species with titania ${ }^{19,34}$ which is a characteristic band of the bidentately bonded (bonded to Ti) sulfate species. The XRD pattern (Figure 8a) has the anatase peak visible at a $2 \theta$ value of $25.3^{\circ}$ as stated earlier, but it is not sharp, and the intensity is low due to the presence of sulfate and ammonium ions present in the sample. The peak around $1400 \mathrm{~cm}^{-1}$ has two possible explanations, one due to the stretching frequency of the $\mathrm{S}=\mathrm{O}$ bond of free sulfate group, the other due to the deformation mode of ammonium. ${ }^{35}$ Howeve, the IR spectrum of the samples observed above $400{ }^{\circ} \mathrm{C}$ does not show this peak, which reveals that the peak is due to the ammonium ion deformation. The $\mathrm{NH}_{4}{ }^{+}$ion begins to decompose at this temperature. The XPS study shows that at $600{ }^{\circ} \mathrm{C}$ there is 1.53 atom \% (Table 3) of nitrogen in the sample which is attributed to the decomposition of the $\mathrm{NH}_{4}{ }^{+}$cation. Above 400 ${ }^{\circ} \mathrm{C}$ ammonium ions are decomposed to produce $\mathrm{N}_{2}$ molecules and NO species as explained in the XPS section 3.3. A further increase in temperature led to the doping of the nitrogen in the titania lattice by the replacement of the oxygen atom. This is confirmed by the XPS peak around $399.7 \mathrm{eV}$ which is due to the formation of an $\mathrm{O}-\mathrm{Ti}-\mathrm{N}$ bond, suggesting that the nitrogen is doped in the lattice as an anion by the oxynitride bond formation $(\mathrm{O}-\mathrm{Ti}-\mathrm{N})$. The interaction of sulfate ion becomes strong above $400{ }^{\circ} \mathrm{C}$ due to the strong binding of $\mathrm{SO}_{4}{ }^{2-}$ with $\mathrm{TiO}_{2}$. This is clearly evident from the IR spectra of the samples calcined at 500 and $600{ }^{\circ} \mathrm{C}$ (Figure 9e and f) where the absorption at $1104 \mathrm{~cm}^{-1}$ is split into three distinct bands (1225, 1145 , and $1044 \mathrm{~cm}^{-1}$ ) due to the lowering of the symmetry of $\mathrm{SO}_{4}{ }^{2-}$ ion from tetrahedral $\left(T_{d}\right)$ to $C_{2 v}$ point group as a result of a bidentate bond on formation of anatase titania. ${ }^{34}$ The XRD of the TNS8 sample at $600{ }^{\circ} \mathrm{C}$ (Figure 8c) displays an intense peak of anatase titania at $2 \theta$ value of 25.3 which shows that the sulfate ion began to decompose at this temperature. This is confirmed by the XRD spectra of TNS8 sample at $700{ }^{\circ} \mathrm{C}$ which shows codoped (N, S) anatase titania without any extra phase (Figure 1b). This sulfate decomposition was in agreement with previous results obtained. ${ }^{23}$ To confirm the effect of ammonium cation and sulfate anion on the anatase structure formation, all calcined TNS8 samples were treated with $1 \mathrm{M} \mathrm{NaOH}$ solution for $24 \mathrm{~h}$. By treatment with $\mathrm{NaOH}$ and further washing with water, both the ammonium and sulfate ions were removed from the calcined samples. The FTIR spectra taken after $\mathrm{NaOH}$ treatment are shown in Figure 10. It reveals the absence of both species (ammonium and sulfate) with the spectra showing only the stretching vibration of the $\mathrm{Ti}-\mathrm{O}-\mathrm{Ti}$ bond below $1000 \mathrm{~cm}^{-1}$, along with the bands around 1600 and $3400 \mathrm{~cm}^{-1}$ corresponding to the bending and stretching of the $\mathrm{OH}$ group of both water molecules occluded and the $\mathrm{OH}$ group adsorbed onto the surface of $\mathrm{TiO}_{2}$. In addition to this the XRD pattern of these $\mathrm{NaOH}$ treated samples shows no other peaks except the peak for anatase titania. At lower temperatures $\left(100\right.$ and $\left.300{ }^{\circ} \mathrm{C}\right)$ TNS8 samples 


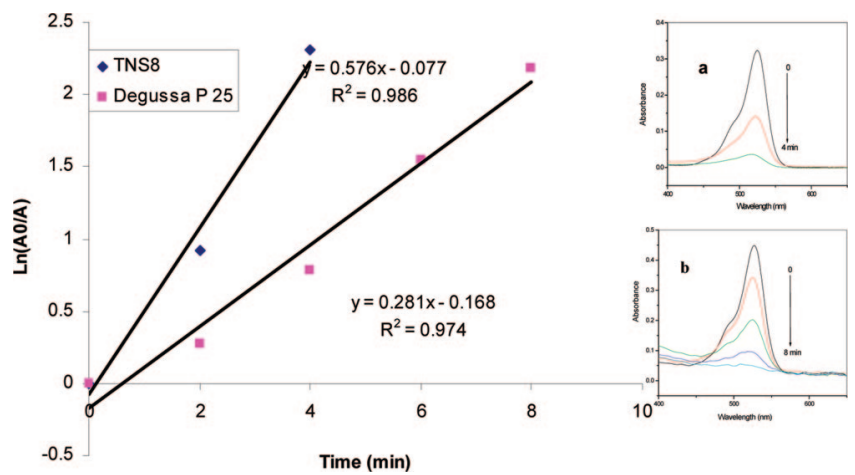

Figure 6. Kinetic data of the Degussa P25 and TNS8 sample calcined at $850{ }^{\circ} \mathrm{C}$ under UV/visible light photocatalysis. (Inset) Absorption spectra of rhodamine dye degradation as a function of time using (a) TNS8 (b) Degussa P 25.

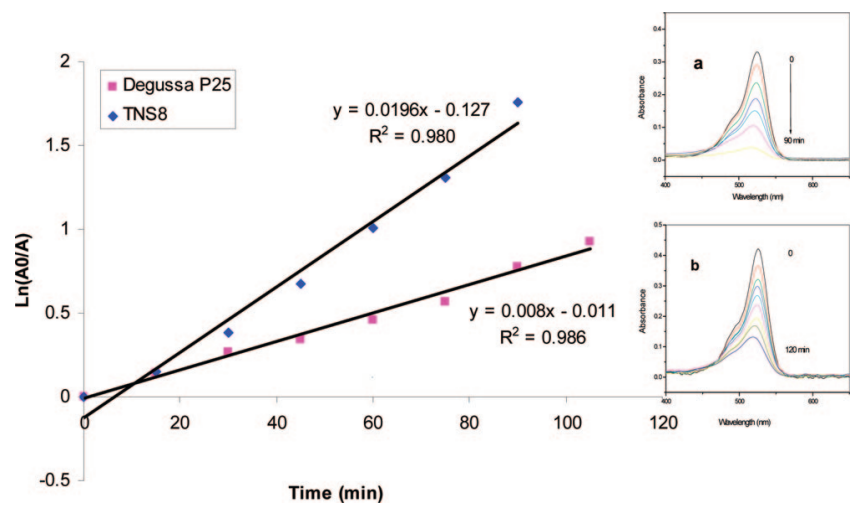

Figure 7. Kinetic data of the Degussa P25 and the TNS8 calcined at $850^{\circ} \mathrm{C}$ under visible light photocatalysis. (Inset) Absorption spectra of rhodamine dye degradation as a function of time using (a) TNS8 (b) Degussa P25. appear less crystalline, whereas the higher-temperature calcined sample $\left(600{ }^{\circ} \mathrm{C}\right)$ has well crystallized anatase titania peaks (Supporting Information 2). This also suggests that both ammonium and sulfate species are capable of inhibiting the crystallization of titania at lower temperature (below $600^{\circ} \mathrm{C}$ ). Therefore, the modification using ammonium sulfate reveals that during the lower heat treatment regime the influence of ammonium ions is predominant, while as the temperature increases the sulfate interaction becomes more prominent. In the present study anatase stability was achieved up to a temperature of $900{ }^{\circ} \mathrm{C}$.

4.2. Photocatalysis. According to literature reports organic dyes such as methylene blue and rhodamine $6 \mathrm{G}$ undergo complete structural degradation by the photocatalytic reaction of $\mathrm{TiO}_{2}$ through several intermediate steps. ${ }^{36-38}$ However, the photocatalytic activity of titania depends upon several factors, such as phase composition (anatase and/or rutile), surface area, crystallinity and crystallite size, absorption properties of the dyes on the surface of $\mathrm{TiO}_{2}$ used, rate of electron-hole recombination, and the number of electrons created. ${ }^{25}$ Which factor dominates the photocatalytic effect of titania is debatable. ${ }^{39} \mathrm{In}$ this study, TNS8 samples calcined at all temperatures $(700,800$, 850 , and $900{ }^{\circ} \mathrm{C}$ ) shows significantly higher photocatalytic activity than the control sample (Table 4) studied under identical conditions. The highest activity is observed for the TNS8 sample calcined at $850{ }^{\circ} \mathrm{C}$. The anatase phase stability of the nanocrystalline $\mathrm{TiO}_{2}$ powders at high calcination temperature and the codoping $(\mathrm{N}, \mathrm{S})$ have a significant influence in improving the photocatalytic activity of these $\mathrm{TiO}_{2}$ samples. Direct comparison of the crystal phase between the control and TNS8 sample shows

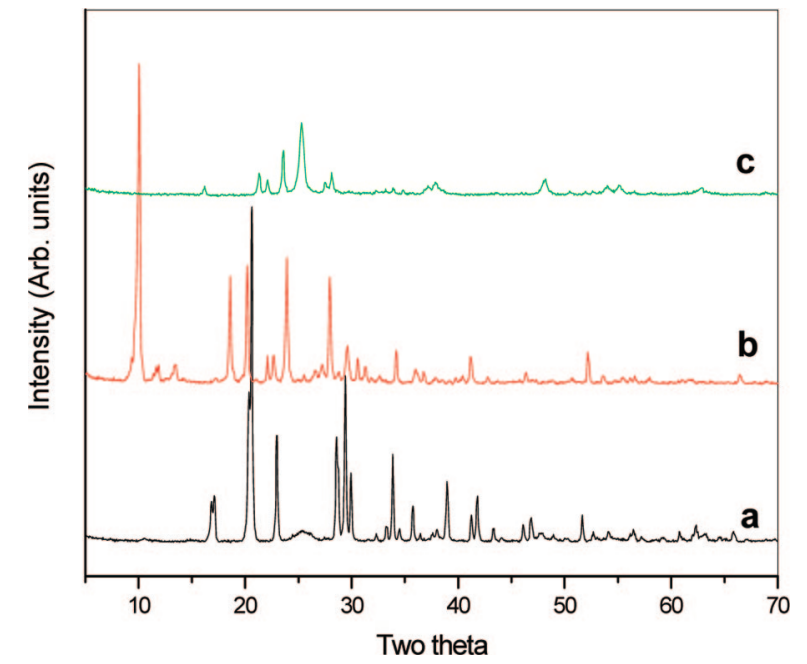

Figure 8. XRD spectra of the precursor samples calcined at (a) 100 , (b) 400 , and (c) $600{ }^{\circ} \mathrm{C}$.

(Table 1) that the control sample is rutile at all temperatures, whereas the TNS8 sample is anatase. Anatase titania has been reported to be more photocatalytically active than the rutile form because the adsorption affinity of the organic dye molecule toward the anatase phase is stronger compared to that of rutile..$^{40,41}$ The adsorption difference of the dye on $\mathrm{TiO}_{2}$ phases is mainly due to the structural difference of anatase and rutile. Both anatase and rutile consist of tetragonal structures having $\left[\mathrm{TiO}_{6}\right]^{2-}$ octahedra, which share edges and corners in a different manner, while keeping the overall stoichiometry as $\mathrm{TiO}_{2}{ }^{32}$ Rutile is characterized by a surface where the dissociation of adsorbed organic molecule takes place more easily than on the anatase. ${ }^{40-42}$ These essential differences in the surface chemistry of the two $\mathrm{TiO}_{2}$ phases can explain their different photocatalytic properties because a photocatalytic reaction mainly takes place at the surface of the catalyst. All the codoped samples (except the TNS 8 at $900{ }^{\circ} \mathrm{C}(41 \%$ anatase)) show only anatase phase, whereas the control samples show rutile phase (only at $700{ }^{\circ} \mathrm{C}$ $18 \%$ anatase phase presented) which explains the main reason for higher photocatalytic activity shown by the codoped samples.

A further factor is the higher surface area of TNS8 samples (Table 2). As the specific surface area of the catalyst increases, it can adsorb a higher number of dye molecules. The TNS8 sample calcined at all temperatures shows the anatase phase with a significantly higher surface area (more than two times higher) compared to that of the control titania (Table 2). A further factor to consider is the effect of codoping $(\mathrm{N}, \mathrm{S})$ which shifts the absorption edge of the titania toward the visible light region (Supporting Information 3) due to the synergistic effects of nitrogen and sulfur. ${ }^{43,44}$ The mixing of $\mathrm{N}_{2 \mathrm{p}}$ with $\mathrm{O}_{2 \mathrm{p}}$ states will effectively lead to the band gap narrowing of titania and the mixing of the $S_{3 p}$ states of sulfur atoms with the valence band increases the width of the valence band which results in the decrease of band gap energy (Supporting Information 4, Table 1). ${ }^{43,44}$ These three factors, i.e., improvement in higher anatase phase stability, surface area, and codoping (N, S) made the TNS8 sample more photocatalytically active than the control sample at all temperatures. Recent reports on the rhodamine dye degradradation mechanism using $\mathrm{TiO}_{2}$ and $\mathrm{TiO}_{2} / \mathrm{SiO}_{2}$ composites showed that the blue shift in absorption maxima represents the dye degradation pathway through the elimination of the diethyl group from the dye structure. ${ }^{36,38}$ In this study a gradual decrease in absorption maxima of the dye without any blue shift (Figures 6 and 7) was observed. Thus, it has been concluded here that active radical species (hydroxyl and super 

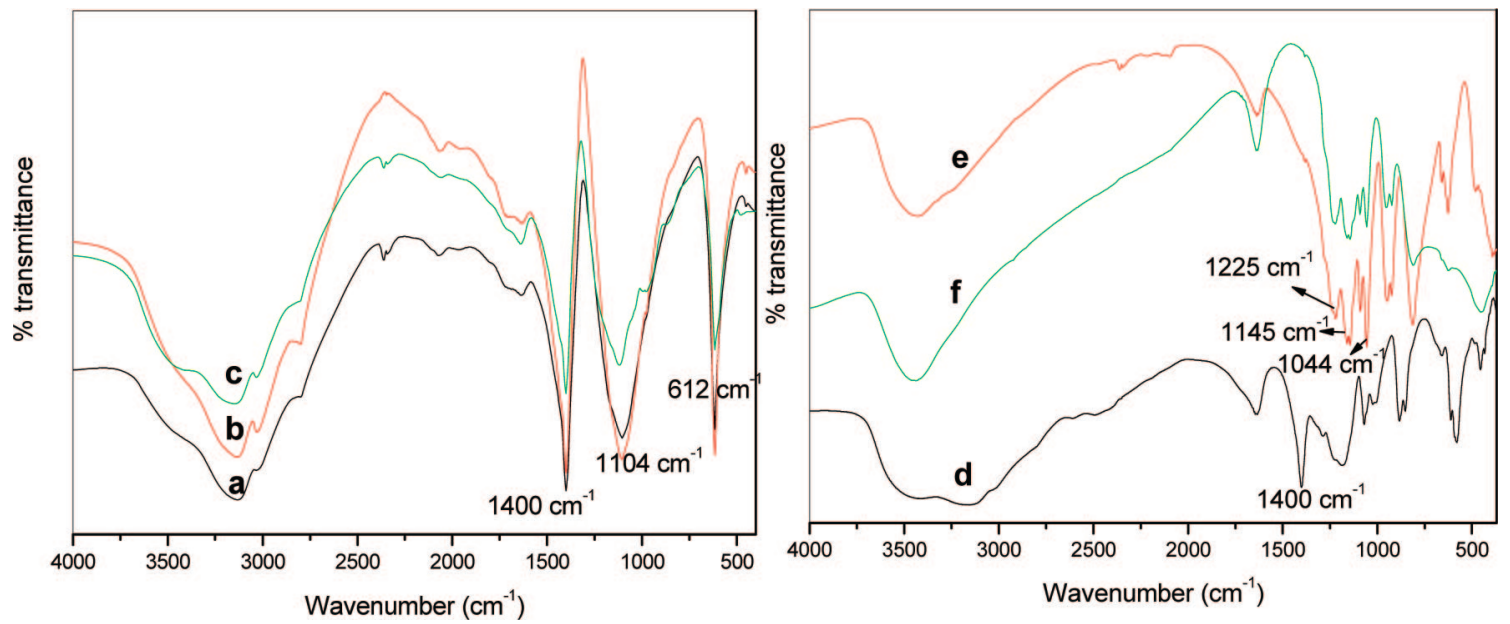

Figure 9. FTIR spectra of the TNS8 samples at (a) 100, (b) 200, (c) 300, (d) 400, (e) 500, and (f) $600{ }^{\circ} \mathrm{C}$.

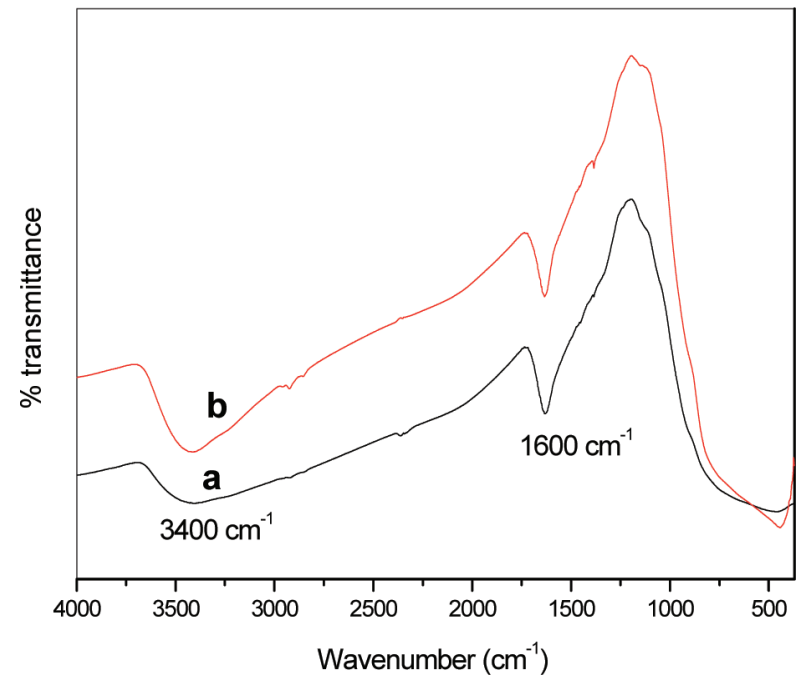

Figure 10. FTIR spectra of the TNS8 samples at (a) 100 and (b) 600 ${ }^{\circ} \mathrm{C}$ after $\mathrm{NaOH}$ treatment.

oxide radicals) generated during photocatalysis attack at the ring structure (chromophore) rather than attacking the diethyl amino group (auxochrome). The photocatalytic activity was also studied using another model pollutant, methylene blue, to confirm the activity of these materials on different organic pollutants. These degradation experiments showed a trend in activity similar to that of the rhodamine $6 \mathrm{G}$ dye degradation (Supporting Information 5).

\section{Conclusions}

Nitrogen, sulfur codoped high-temperature stable visible light active anatase titania was successfully synthesized by chemical modification of the precursor titanium isopropoxide using ammonium sulfate. These materials were characterized by various techniques such as XRD, Raman spectroscopy, FTIR, XPS, and BET surface area analysis. The phase analysis by XRD found the 1:8 TTIP: $\left(\mathrm{NH}_{4}\right)_{2} \mathrm{SO}_{4}$ composition (TNS8) was the most effective in extending the anatase-to-rutile phase transformation. It showed the formation of $100 \%$ anatase at $850{ }^{\circ} \mathrm{C}$ and $41 \%$ anatase at $900{ }^{\circ} \mathrm{C}$, whereas the control titania completely transformed to rutile at $800{ }^{\circ} \mathrm{C}$ with only $12 \%$ anatase at $700{ }^{\circ} \mathrm{C}$. XPS studies showed that nitrogen is doped as an anion and sulfur as a cation. All the doped samples showed significantly higher photocatalytic activity compared to the control titania. The visible light photocatalytic activity comparison of the TNS8 sample calcined at higher temperature 850 ${ }^{\circ} \mathrm{C}$ with that of a commercial catalyst Degussa P25 showed that TNS8 has twice the activity of Degussa P25 and the rate constant calculated from first-order kinetics was $0.019 \mathrm{~min}^{-1}$ for TNS8 and $0.008 \mathrm{~min}^{-1}$ for Degussa P25, while the control sample showed a negligible amount of activity at this temperature. These $\mathrm{N}, \mathrm{S}$ codoped samples also showed excellent photocatalytic activity in UV/visible light. The TNS8 composition calcined at $850^{\circ} \mathrm{C}$ decolorized the rhodamine $6 \mathrm{G}$ dye within $4 \mathrm{~min}$ (pseudofirst-order rate constant $0.576 \mathrm{~min}^{-1}$ ), whereas the Degussa P25 under identical conditions decolorized the dye only after $8 \mathrm{~min}$ (rate constant $0.281 \mathrm{~min}^{-1}$ ). This higher photoactivity was explained by an improvement in anatase phase stability and higher surface area along codoping $(\mathrm{N}, \mathrm{S})$ in the titania lattice.

Acknowledgment. One of the authors, P.P., acknowledges R\&D Strand I award 2005 from DIT. We thank Enterprise Ireland for financial support. We thank Dr. Anthony Betts and Dr. Hugh Hayden for their valuable comments.

Supporting Information Available: Figures giving type I isotherms of samples calcined at $800{ }^{\circ} \mathrm{C}, \mathrm{XRD}$ patterns of the TNS8 samples at 100 and $600{ }^{\circ} \mathrm{C}$ after $\mathrm{NaOH}$ treatment, absorption spectra and reflectance spectra, band gaps of the N, $\mathrm{S}$ codoped sample calcined at different temperatures, absorption spectra and kinetic analysis of methylene blue degradation. This material is available free of charge via the Internet at http:// pubs.acs.org.

\section{References and Notes}

(1) Kamat, P. V. J. Phys. Chem. C 2007, 111, 2834. Parkin, I. P.; Palgrave, R. G. J. Mater. Chem. 2005, 15, 1689.

(2) Pillai, S. C.; Periyat, P.; George, R.; McCormack, D. E.; Seery, M. K.; Hayden, H.; Colreavy, J.; Corr, D.; Hinder, S. J. J. Phys. Chem. C 2007, 111, 1605 .

(3) Chen, X; Mao, S. S. Chem. Rev 2007, 107, 2891. Yamagishi, M.; Kuriki, S.; Song, P. K.; Shigesato, Y. Thin Solid Films 2003, 442, 227.

(4) 4 Bach, U.; Corr, D.; Lupo, D.; Pichot, F.; Ryan, M. Adv. Mater. 2002, 14, 845 .

(5) Hoffmann, M. R.; Martin, S. T.; Choi, W.; Bahnemann, D. W. Chem. Rev. 1995, 95, 69. Yang, S. W.; Gao, L. J. Am. Ceram. Soc. 2005, 88, 968.

(6) Stafford, U.; Gray, K. A.; Kamat, P. V.; Varma, A. Chem. Phys. Lett. 1993, 205, 55.

(7) Riegel, G.; Bolton, J. R. J. Phys. Chem. 1995, 99, 4215.

(8) Baiju, K. V.; Periyat, P.; Wunderlich, W.; Pillai, K. P.; Mukundan, P.; Warrier, K. G. K. J. Sol-Gel Technol. 2007, 43, 283. 
(9) Padmanabhan, S. C.; Pillai, S. C.; Colreavy, J.; Balakrishnan, S.; McCormack, D. E.; Perova, T. S.; Gun'ko, Y.; Hinder, S. J.; Kelly, J. M. Chem. Mater. 2007, 19, 4474.

(10) Kumar, K. N. P.; Keizer, K.; Burggraaf, A. J. Nature 1992, 358, 48. Czanderna, A. W.; Rao, C. N. R.; Honig, J. M. Trans. Faraday Soc. 1958, 54, 1069.

(11) Machida, M.; Norimoto, W. K.; Kimura, T. J. Am. Ceram. Soc. 2005, $88,95$.

(12) Hurum, D. C.; Agrios, A. G.; Gray, K. A. J. Phys. Chem. B 2003, 107, 10871.

(13) Periyat, P.; Baiju, K. V.; Pillai, K. P.; Mukundan, P.; Warrier,

K. G. K. Appl. Catal., A 2008, 349, 13.

(14) Francico, M. Z. P.; Mastelaro, V. R. Chem. Mater. 2002, 14, 2514.

(15) Reidy, D. J.; Holmes, J. D.; Nagle, C.; Morris, M. A. J. Mater. Chem. 2005, 15, 3494.

(16) Periyat, P.; Baiju, K. V.; Mukundan, P.; Pillai, P. K.; Warrier, K. G. K. J. Sol-Gel Technol. 2007, 43, 299.

(17) Colon, G.; Hidalgo, M. C.; Munuera, G.; Ferino, I.; Cutrufello, M. G.; Navio, J. A. Appl. Catal., B 2006, 67, 41. Colon, G.; Espana, J. M. S.; Hidalgo, M. C.; Navýo, J. A. J. Photochem. Photobiol. A: Chem. 2006, 179, 20.

(18) Colon, G.; Hidalgo, M. C.; Munuera, G.; Ferino, I.; Cutrufello, M. G.; Navio, J. A. Appl. Catal., B 2006, 63, 45.

(19) Bokhimi, X.; Morales, A.; Lopez, T.; Gomez, R.; Navarrete, J. J. Sol-Gel Sci. Tech. 2004, 29, 31. Bokhimi, X.; Morales, A.; Novaro, O. Chem. Mater. 1997, 9, 2616.

(20) Ortiz-Islas, E.; Lopez, T.; Navarrete, J.; Bokhimi, X.; Gomez, R. J. Mol. Catal A: Chem. 2005, 228, 345.

(21) Yan, M.; Chen, F.; Zhang, J.; Anpo, M. J. Phys. Chem. B 2005, 109, 8673.

(22) Bokhimi, X.; Morales, A.; Novaro, O. Chem. Mater. 1997, 9, 2616.

(23) Periyat, P.; Pillai, S. C.; McCormack, D. E.; Colreavy, J.; Hinder, S. J. J. Phys. Chem. C 2008, 112, 7644.

(24) Sakthivel, S.; Janczarek, M; Kisch, H. J. Phys. Chem. B 2004, 108, 19384. Ho, W.; Yu, J. C.; Lee, S. J. Solid State Chem. 2006, 179, 1171.

(25) Choi, S. Y.; Mamak, M.; Coombs, N.; Chopra, N.; Ozin, G. A. Adv. Funct. Mater. 2004, 14, 335.
(26) Pal, M.; Serrano, J. G.; Santiago, P.; Pal., U. J. Phys. Chem. C 2007, 111, 96

(27) Irie, H.; Watanabe, Y.; Hashimoto, K. J. Phys. Chem. B 2003, 107 5483. Chen, X.; Burda, C. J. Phys. Chem. B 2004, 107, 5483. Chen, X.; Lou, Y.; Samia, A. C. S.; Burda, C.; Gole, J. L. Adv. Funct. Mater. 2005, 15,41

(28) Yu, J. C.; Ho, W.; Yu, J.; Yip, H.; Wong, P. K.; Zhao, J. Environ. Sci. Technol. 2005, 39, 1175.

(29) Ohno, T.; Akiyoshi, M.; Umebayashi, T.; Asai, K.; Mitsui, T.; Matsumura, M. Appl. Catal., A 2004, 265, 115.

(30) Bringer, C. J.; Scherer, G. W. Sol-Gel Science; Academic Press: New York, 1990

(31) Schubert, U. J. Mater. Chem. 2005, 15, 3701.

(32) Gopal, M.; Chan, W. J. M.; De Jonghe, L. C. J. Mater. Sci. 1997, 32,6001 .

(33) Xie, C.; Yang, Q.; Xu, Z.; Liu, X.; Du, Y. J. Phy. Chem. B 2006 110, 8587. Yamabi, S.; Imai, H. Thin Solid Films 2003, 434, 86.

(34) Samantaray, S. K.; Mohapatra, P.; Parida, K. J. Mol. Catal. A: Chem. 2003, 198, 277.

(35) Rhee, C. H.; Lee, J. S.; Chung, S. H. J. Mater. Res. 2005, 20, 3011. (36) Wilhelm, P.; Stephan, D. J. Photochem. Photobiol. A: Chem. 2007,

$185,19$.

(37) Aronson, B. J.; Blanford, C. F.; Stein, A. Chem. Mater. 1997, 9, 2842. Beyers, E.; Cool, P.; Vansant, E. F. J. Phys. Chem. B 2005, 109 10081. Busuioc, A. M.; Meynen, V.; Beyers, E.; Mertens, M.; Cool, P.; Bilba, N.; Vansant, E. F. Appl. Catal., A 2006, 312, 153.

(38) Chen, F.; Zhao, J.; Hidaka, H. Int. J. Photoenergy 2003, 5, 209.

(39) Ryu, J.; Choi, W. Environ. Sci. Technol. 2008, 42, 294.

(40) Su, W.; Zhang, J.; Feng, Z.; Chen, T.; Ying, P.; Li, C. J. Phys. Chem. C 2008, 112, 7710 .

(41) Ramis, G.; Busca, G.; Lorenzelli, V. J. Chem. Soc. Faraday Trans. I 1987, 83, 1591 .

(42) Hadjivanov, K. Appl. Surf. Sci. 1998, 135, 331.

(43) Burda, C.; Lou, Y. B.; Chen, X. B.; Samia, A. C. S.; Stout, J.; Gole, J. L. Nano Lett. 2003, 3, 1049.

(44) Umebayashi, T.; Yamaki, T.; Tanala, S.; Asai, K. Chem. Lett. 2003, 32,330 .

JP808444Y 